\title{
Managerial and Ergonomic Measures for Reducing Psychosocial Risk Factors in the Workplace Under COVID-19
}

\author{
Dr. Magdalena Parcheva \\ University of Economics - Varna, Varna, Bulgaria \\ m.parcheva@ue-varna.bg
}

\begin{abstract}
Under COVID-19, organisations are in a crisis situation. Challenging are topics related to business survival, changing work processes and managing the psychosocial risk. The subject of research in the article are the psychosocial risk factors in the workplace, their manifestations in the pandemic and the management and ergonomic measures for their impact reduction. The following main goals have been achieved: the theoretical foundations of the issue of psychosocial risks have been discussed, their specifics in the crisis have been highlighted, the results of an empirical survey in organisations in the transport sector have been presented, conclusions and recommendations from the study have been formulated.
\end{abstract}

Keywords: psychosocial risk factors, workplace safety and health, COVID-19, psychosocial risk assessment, human factors and ergonomics.

JEL Code: M1, M54 DOI: https://doi.org/10.36997/IJUSV-ESS/2020.9.1.109

\section{Въведение}

В условия на динамичност на средата, бързо развитие и приложение на съвременните информационни и комуникационни технологии, роботизация на производството, демографски промени и нов работен свят, предмет на нарастващ изследователски интерес са трудовите процеси в организацията. Проследявайки теоретичните и емпиричните проучвания в областта, можем да откроим два аспекта от интерес в съвременните студии:

(a) възможностите за заместване на човешкия труд от роботизираните технологии и компютъризираните информационни системи и свързаните с това промени в трудовите процеси и компетентности на специалистите;

(б) психосоциалните рискови фактори и възможността за намаляване на тяхното въздействие чрез мерки в контекста на системата за безопасни и здравословни условия на труд, постигане на ергономичност на средата и средствата за производство, чрез подходящи управленски подходи и социално отговорни практики.

Пандемията COVID-19 постави големи предизвикателствата пред икономиката, здравните и социалните системи и публичните политики на държавите в глобален мащаб. Стопанските организации са поставени в кризисна ситуация, която рефлектира върху бизнеса, променя условията на труд, трудовите процеси, подсилва въздействието на психосоциалните рискове, пораждат се нови психосоциални рискови фактори.

В този смисъл предмет на изследване в статията са свързаните с труда психосоциални рискови фактори, специфичните проявления на психосоциалните рискове в условия на COVID-19 и управленските и ергономичните мерки за намаляване на тяхното въздействие.

Основните цели на статията се съсредоточават в направленията:

(1) дискутиране на теоретичните основи на проблематиката за психосциалните рискови фактори на работното място;

(2) открояване на психосоциалните рискове в резулат COVID-19;

(3) представяне на резултати от емпирично проучване за промените в трудовите процеси и психосоциалните рискови фактори в организации от сектор транспорт;

(4) формулиране на изводи и препоръки от изследването. 


\section{1. Психосоциални рискови фактори: теоретични аспекти}

Психосоциалните рискови фактори са предизвикателство пред управлението на съвременната организация. Тенденции като глобализация, интернационализация, дигитализация, технологично развитие, увеличаване на интензивността на труда и демографски промени трансформират трудовите процеси, съдържанието на работните задачи, работната среда, техническите средства, компютьризираните информационни системи. Това предполага преосмисляне на традиционните управленски практики и бизнес модели за постигане на по- висока ефективност и ефикасност, търсене и приложение на нови компетентностни модели за кадрите, засилване на акцента върху осигуряването на здравословни и безопасни условия на труд с оглед по-висока продуктивност, мотивация и опазване на физическото и психическото здраве и благосъстояние на специалистите.

Психосоциалните рискови фактори са сред основните причини за стрес в резултат трудова дейност. Стресът се дефинира като състояние, което се придружава от физически, психологически и социални оплаквания и което е резултат от неспособността на индивида да преодолее несъответствието между изисквания на работното място и очаквания (European Social Partners, 2004).

Стресьт допринася за редица заболявания като кардиоваскуларни заболявания, мускулноскелетни смущения, проблеми с имунитета и с менталното здраве. Според данните от проучване на Eurofound (2012) 2,5\% от обхванатите в изследването служители са с влошено здравословно състояние, като 47\% съобщават за повече от два здравословни проблема със силна взаимовръзка между физическо и психическо състояние. По данни на European Agency for Safety and Health at Work (2018) две трети от работещите в Европейския съюз са изложени на риск от стрес, породен от трудова дейност. В проучване на European Agency for Safety and Health at Work (2018) се констатира тенденция организациите, преди всичко малките и средните предприятия, да обръщат внимание по-скоро на традиционните аспекти, свързани с безопасните и здравословните условия на труд като параметри на работната среда (осветеност, влажност, шум, дизайн на техническите средства и работното място според антропологичните характеристики на човека), отколкото на психосоциалните рискови фактори, въпреки тяхната значимост.

Ключова характеристика на психосоциалните фактори на работното място е, че те от една страна са породени от обективни специифики на вътрешната среда в организацията като управленска система, процедури, стил на ръководство, организация на труда, социални взаимоотношения, работни задачи, а от друга страна са пряко свързани със субективните възприятия и усещзания на всеки от специалистите. В този смисъл проблематиката за измерване, оценка и намаляване на въздействието на психосоциалните рискови фактори е с интердисциплинарен характер и изисква интегриране на знание от областите: управление, психология, когнитивна и организационна ергономия.

International Labor Office (1986) дефинира психосоциалният риск като взаимодействие между групите фактори: (1) съдържание на трудовите задачи; (2) организация на труда и управление; (3) други условия на средата в рамките на предприятието и извън предприятието; (4) знания и умения на кадрите; (5) потребности на отделния специалист като сигурност, себереализация, уважение, признание. Leka, St. et. al. (2017) пишат, че психосоциалните рискови фактори се отнасят до аспектите проектиране и управление на трудовите процеси и техния социален и организационен контекст. Психосоциалните фактори са свързани с вероятността за негативно въздействие върху здравето на служителите. В International Organization for Standardisation (1996) EN ISO 10075-1:1996 "Ergonomic principles related to workload" се посочват следните характеристики, водещи до умствено натоварване и стрес: неяснота на целите и задачите, сложност на задачите, изисквания за продължително умствено натоварване, неадекватни и неясни указания и информация, подкрепа от ръководството. 
В свое изследване International Labour Organisation (2012) открояват фактори, които имат въздействие върху причинителите на стрес на работното място и следва да бъдат предмет на оценка и управленски мерки: (1) лидерство и справедливост в отношенията към специалистите; (2) изисквания на работното място; (3) осигуряване на възможност на специалистите сами да организират начина на изпълнение на трудовите задачи; (4) социална подкрепа; (5) физически характеристики на работната среда; (6) баланс „труд- свободно време“; (7) признание за положения труд; (8) защита от насилие; (9) сигурност на работното място; (10) информация и комуникация.

В теоретичен план проблематиката за психосоциалните рискови фактори е предмет на изследователски интерес. Проследявайки теоретичните и емпиричните проучвания в областта могат да бъдат откроени теоретични модели и метричен инструментариум за оценка. Модельт „потребност - контрол- подкрепа“ се фокусира върху връзката между изисквания на работното място, самостоятелност на специалиста в изпълнение на трудовите задължения и срес (Karasek, 1979, Karasek and Thoerell, 1990). Изискванията на работното място се характеризират с показателите: специфика на задачите и интензивност на труда. Според тези показатели учените обособяват четири типа работни места: (а) работни позиции с ниско напрежение /ниски изисквания и висока степен на самостоятелност; (б) пасивни работни позиции /ниска степен на самостоятелност и ниски изисквания/; (в) работни позиции с високо напрежение /високи изисквания на дльжността и ниска степен на самостоятелност; (г) активни работни позиции /високи изисквания на длъжността и висока степен на самостоятелност/. Високите изисквания водят до високи нива на стрес, но предоставянето на самостоятелност редуцира възприятието за стрес на специалистите. Социалната подкрепа от рьководители и колеги играе ролята на буфер и намалява възприятието за стрес. В своя модел Siegrist (2002) акцентира върху баланса между усилия на специалиста, стимули на работното място, негативни емоции и стрес. Ученият разглежда следните стимули: сигурност на работното място, заплата, уважение и признание, статус, кариерно израстване. Усещането за дисбаланс между усилия и стимули е рисков фактор за здравето. Paskvan, Kubicek изследват ефектите от повишаване на интензивността на труда и подчертават, че доверието, съветите от ръководители и колеги и стимулите са фактори, които подпомагат специалистите да се справят с предизвикателствата на трудовата дейност. Специалистите на по-висока възраст и с по- голям професионален опит, работещи на позиции, характеризиращи се с високо натоварване и интензивност, са по- продуктивни и риска за тяхното здраве е по- мальк при позитивен социиален климат в организацията и подкрепа от рьководството. Повишаването на интензивността на труда увеличава значението на самоконтрола и уменията за управление на времето за посрещане на изискванията на работното място и за борба с хроничния стрес.

Albertsen et. al. правят проучване сред 349 специалиста, упражняващи интелектуален труд и показва позитивна връзка между количествените изисквания, конфликтите, липсата на яснота за ролята на специалиста, липса на признание и симптомите на стрес, причинен от умствено натоварване. Liorens et. al. проучва 7612 трудещи се и доказва зависимост между психосоциалните рискови фактори и управленските практики. Благоприятната психосоциална среда се асоциира със стил на ръководство с участие на специалистите, постоянни трудови договори, възприятие на служителите, че те не могат да бъдат лесно заменени, слаба авторитарност и агресивност, възможност за кариерно развитие, заплащане на отработените часове, работно време между 31 и 40 часа на седмица, редовни смени (при сменен режим на работа).

Обобщението и интерпретацията на различни теоретични и практико- приложни изследвания с предмет психосоциалните рискови фактори позволява да бъдат откроени аспекти на психосоциалната работна среда и тяхното отражение върху стопанската организация (табл. 1). 
Таблица 1 Психосоциална работна среда - аспекти и въздействие върху организацията

\begin{tabular}{|c|c|}
\hline $\begin{array}{c}\text { Аспекти на психосоциалната } \\
\text { работна среда }\end{array}$ & $\begin{array}{c}\text { Рискова психосоциална работна } \\
\text { среда- въздействие върху } \\
\text { организацията }\end{array}$ \\
\hline $\begin{array}{cl}\text { Длъжност } \\
\text { - } \\
\text { Изисквания на длъжността: } \\
\text { съдържание и специфика на } \\
\text { работните задачи, компетентности } \\
\text { - } \\
\text { Роля на специалиста: яснота на } \\
\text { ролята, ролеви конфликт } \\
\text { - } \\
\text { Смисъл от труда } \\
\text { - Самостоятелност при изпълнение } \\
\quad \text { на работните задачи }\end{array}$ & $\begin{array}{c}\text { Въздействие върху здравето } \\
\text { - } \quad \text { Емоционални, когнитивни и } \\
\text { поведенчески реакции на стреса: } \\
\text { раздразнителност, умора, } \\
\text { отдръпване и намаляване на } \\
\text { ангажираността със задачите, } \\
\text { затруднена концентрация и } \\
\text { запомняне } \\
\text { - } \text { Смущения в съня } \\
\text { - Главоболие } \\
\text { - } \\
\text { Кардиоваскуларни проблеми, } \\
\text { мускулноскелетни смущения, } \\
\text { ендокринни и имунни реакции }\end{array}$ \\
\hline $\begin{array}{ll}\text { Трудови процеси } \\
\text { - } \\
\text { Организация на труда: гъвкавост } \\
& \text { на работното време, график, } \\
& \text { ротация } \\
\text { - } & \text { Инивидуална/ екипна работа } \\
\text { - } & \text { Автоматизация на трудовите } \\
& \text { процеси } \\
\text { - } & \text { Социални взаимоотношения } \\
\text { - } & \text { Баланс „труд- свободно време“ }\end{array}$ & $\begin{array}{l}\text { Въздействие върху продуктивността от } \\
\text { труда на специалистите } \\
\text { - } \quad \text { Намалена продуктивност от труда } \\
\text { - } \text { Ниска мотивация за работа } \\
\text { - } \text { Неефективно изпълнение на } \\
\quad \text { работните задачи: неспазване на } \\
\text { срокове, пропуски и грешки } \\
\text { - Влошени взаимоотношения с } \\
\quad \text { колегите }\end{array}$ \\
\hline $\begin{array}{c}\text { Безопасни и здравословни условия на } \\
\text { труд } \\
\text { - } \\
\text { Политика за безопасност и здраве } \\
\text { - } \text { Оцаботното място } \\
\text { - } \\
\quad \text { Мерки за управление на } \\
\quad \text { психосоциалния риск }\end{array}$ & 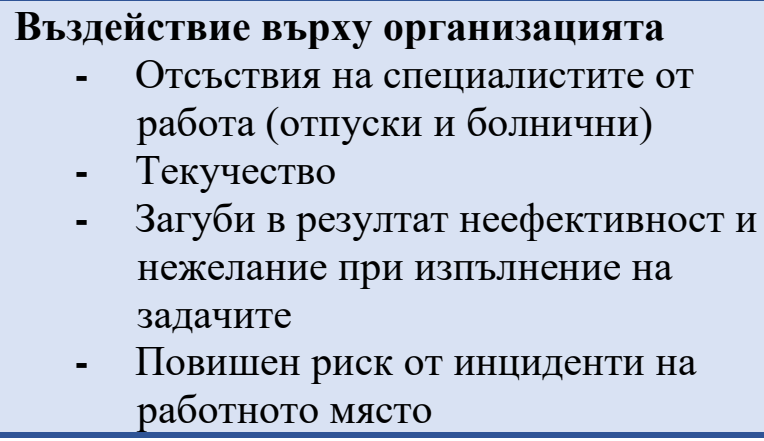 \\
\hline $\begin{aligned} & \text { Управленска система } \\
& \text { - } \text { Стил на рьководство } \\
& \text { - } \text { Политика за стимулиране на } \\
& \text { кадрите: възнаграждения, } \\
& \text { кариерно израстване, обучения, } \\
& \text { постоянни трудови договори } \\
& \text { - } \text { Организационна култура: доверие, } \\
& \text { трудови ценности, чувство за } \\
& \text { общност, сигурност } \\
& \text { - } \text { Социална отговорност }\end{aligned}$ & $\begin{array}{l}\text { Социална отговорност и } \\
\text { конкурентоспособност на } \\
\text { организацията } \\
\text { - } \quad \text { Влошен имидж } \\
\text { - } \quad \text { Ниска степен на предприемаческа } \\
\quad \text { активност } \\
\text { - } \quad \text { Негативно въздействие върху } \\
\quad \text { конкурентоспособността на } \\
\quad \text { организацията в дългосрочен план }\end{array}$ \\
\hline
\end{tabular}

Източник: таблицата е разработена от автора на база анализ на Kiss, et. al. (2013), European Agency for Safety and Health at Work. Healthy Workplaces (2018) и Fernandes, C., Pereira, A. (2016) 
Аспектите, формиращи психосоциалната работна среда в стопанската организация трябва да бъдат предмет на оценка на риска, въз основа на която да се предприемат навременни мерки с превантивен и корективен характер с цел намаляване на вредното влияние на психосоциалните фактори, подобряване на трудовите процеси и осигуряване на безопасни и здравословни условия на труд.

Оценката на рисковите фактори на работното място и приложението на политика по превенция е задължение на работодателя съгласно европейски директиви, стандарти и нормативни документи. Необходимостта от анализ и оценка на психосоциалните фактори, водещи до стрес на работното място е породена не само от законовите разпоредби за безопасност и здраве. Тя е предпоставка при тьрсене на възможности за подобряване на условията на труд и като цяло на управленската система в организацията чрез приложение на социално отговорни практики.

\section{2. Пандемията COVID-19 и свързаните с труда психосоциални рискови фактори}

Пандемията, породена от COVID-19 оказва изключително негативно въздействие върху пазарите на труда: закриване на работни места, загуби от работно време. По прогнозни данни на International Labor Organization/ ILO Monitor (2020) в световен мащаб през второто тримесечие на 2020 г. в сравнение със същия период за 2019 г. се очакват загуби от работно време от 17,3\% или 495 милиона работни места, еквивалентни на пълна заетост. През третото тримесечие на 2020 г. се очаква загубите в сравнение с третото тримесечие на 2019 г. да са 12,1\% или 345 милиона работни места, еквивалентни на пълна заетост. Тези загуби са най- значителни в държавите със средни и ниски доходи.

COVID-19 постави в кризисна ситуация стопанските организации като е засегнат всеки бранш. Значителни са предизвикателствата, както пред публичните политики, така и пред управлението на организациите. Паралелно с въпросите за действие в кризисна обстановка и оцеляване на бизнеса на преден план излизат изискванията за безопасност и здраве на работното място, идентифицирането и търсенето на подходи и възможности за намаляване на въздействието на свързаните с труда психосоциални рискови фактори.

B резултат COVID-19 се пораждат нови психосоциални рискови фактори, както за трудещите се, физически изпълняващи дейността си на работните си места в съответната организация или институция, така и за хората, работещи от своя дом с помощта на съвременните информационни и комуникационни технологии и технически средства.

Базирайки се на изследване на International Labor Organization (2020) могат да се откроят следните психосоциални рискови фактори в условия на COVID-19:

(a) Психосоциални рискови фактори в процеса на труд, осъществяван физически на работното място: увеличено натоварване, удължено работно време, липса на възможност за почивка, страх от заразяване на работното място и предаване на вируса в семейството, опасения, че на работното място не се спазват задължителните противоепидемични мерки.

(б) Психосоциални рискови фактори в процеса на дистанциионна работа, осъществявана с помощта на съвременните информационни комуникационни технологии и технически средства: нарушаване на баланса труд - лично свободно време и време за семейството, изолация, неергономичен дизайн на обособеното работно място в домашни условия, повишени изисквания на работното място, съчетани с липса на подкрепа, чувство за загуба на смисъл от труда.

(в) Психосоциални рискови фактори от общ характер: страх от заразяване и болест, несигурност за работното място, опасения за загуба на доходи, липса на разяснения и подкрепа от страна на ръководството на предприятието при необходимост от свиване на дейността и реструктуриране на бизнеса, социална изолация извън работното място в следствие рестрикциите. 


\section{проучване}

3. Психосоциални рискови фактори в условия на COVID-19: емпирично

C цел проследяване отражението на пандемията COVID-19 върху бизнеса, както и на предприетите и планираните управленски и ергономични мерки е проведено емпирично анкетно проучване сред 25 организации с предмет на дейност обществен транспорт (градски транспорт, междуселищен и международен транспорт), транспорт на туристи, товарен трансnорт. Проучването е осъществено по електронен път през м. август 2020 година. Профильт на обхванатите предприятия е:

(a) организации, опериращи в национален мащаб и оператори за обществен транспорт от Североизточен и Югоизточен район;

(б) брой заети: 36\% с персонал от 1 до 9; 32\% от 10 до 49 заети; 20\% от 50 до 249 заети; $12 \%$ над 249 заети;

(в) автопарк: 48\% с по- малко от 10 превозни средства; 4\% с превозни средства между 11 и 30; 20\% между 31 и 100 превозни средства; 28\% над 100 превозни средства.

Анализът на сферата на дейност на проучените фирми показва, че големите предприятия от сектор „транспорт“ са активни в широк спектър от дейности: пътнически транспорт, логистична дейност и складове, туроператор и турагент (транспорт на туристи, организация и провеждане на екскурзии и събития, продажба самолетни билети), хотелиерство, комбинация от пътнически и товарен транспорт, автомивка, зелена енергия, продажба и ремонт на превозни средства, таксиметров транспорт, служебен транспорт.

Кризата, породена от COVID-19 се е отразила върху дейността на анкетираните организации. Всички предприятия реализират финансови загуби. Преобладаващата част от респондентите (18) посочват, че са съкратили своята дейност - 12 организации са извършили съществено съкращение, а 6 - частични съкращения на дейността. Три оператора за обществен транспорт поради спецификата на сферата, не са свили дейността си, но са реализирали значителни финансови загуби. Предвид изискванията в условия на пандемия COVID-19 във всички организации се осъществяват мерките: (а) информираност на служителите за рисковете от вируса и за предпазните мерки; (б) предоставяне/ използване на лични предпазни средства от работещите и регулярна дезинфекция; (в) ограничаване на посещенията в офиса. Интерес представляват предприетите мерки по отношение на персонала и трудовите процеси в обхванатите в проучването предприятия (табл. 2).

Таблица 2 Реализирани мерки по отношение на персонала и процесите на труд в условия на COVID-19: емпирично проучване

\begin{tabular}{|c|c|c|}
\hline \multirow[t]{2}{*}{ Мярка } & \multicolumn{2}{|c|}{ Приложение на мярката } \\
\hline & Да & He \\
\hline Съкращаване на персонал & $\begin{array}{c}36 \% \\
\text { (9 организации) }\end{array}$ & $\begin{array}{c}64 \% \\
\text { (16 организации) }\end{array}$ \\
\hline Платен/ неплатен отпуск за персонала & $\begin{array}{c}60 \% \\
(15 \text { организации) }\end{array}$ & $\begin{array}{c}40 \% \\
\text { (10 организации) }\end{array}$ \\
\hline Намалено работно време & $\begin{array}{c}40 \% \\
\text { (10 организации) }\end{array}$ & $\begin{array}{c}60 \% \\
\text { (15 организации) }\end{array}$ \\
\hline $\begin{array}{l}\text { Дистанционна работа за част от } \\
\text { персонала }\end{array}$ & $\begin{array}{c}20 \% \\
\text { (5 организации) }\end{array}$ & $\begin{array}{c}80 \% \\
(20 \text { организации) }\end{array}$ \\
\hline $\begin{array}{l}\text { Промени в организацията на работа } \\
\text { (работен график, задължения) }\end{array}$ & $\begin{array}{c}40 \% \\
(10 \text { организации) }\end{array}$ & $\begin{array}{c}60 \% \\
(15 \text { организации) }\end{array}$ \\
\hline
\end{tabular}

Най- често прилаганата мярка в кризисната ситуация е ползване на платен и неплатен отпууск за персонала. Значителна част от организациите (40\%) работят на намалено работно 
време или са осъществили промени в процесите на труд, свързани с изменения в работния график и задълженията на служителите (40\% от респондентите). Дистанционната работа с помощта на съвременните информационни и комуникационни технологии не е често прилагана мярка по отношение на част от персонала с административни функции в анкетираните предприятия. Кризата в резултат COVID-19 е довела до съкращения на персонал в 9 предприятия (36\%).

Развитието на епидемичната обстановка извежда на преден план необходимостта от планиране на мерки, предприемане и реализиране на конкретни действия от стопанските организации с цел оцеляване на бизнеса, в които съществена част трябва да бъде екшън плана за безопасност и здраве и препроектирането на трудовите процеси, като не следва да се пренебрегват подходите за редуциране на въздействието на психосоциалните рискови фактори. В този смисъл в проучването бе включен въпроса относно планираните мерки в тази посока (фиг. 1).

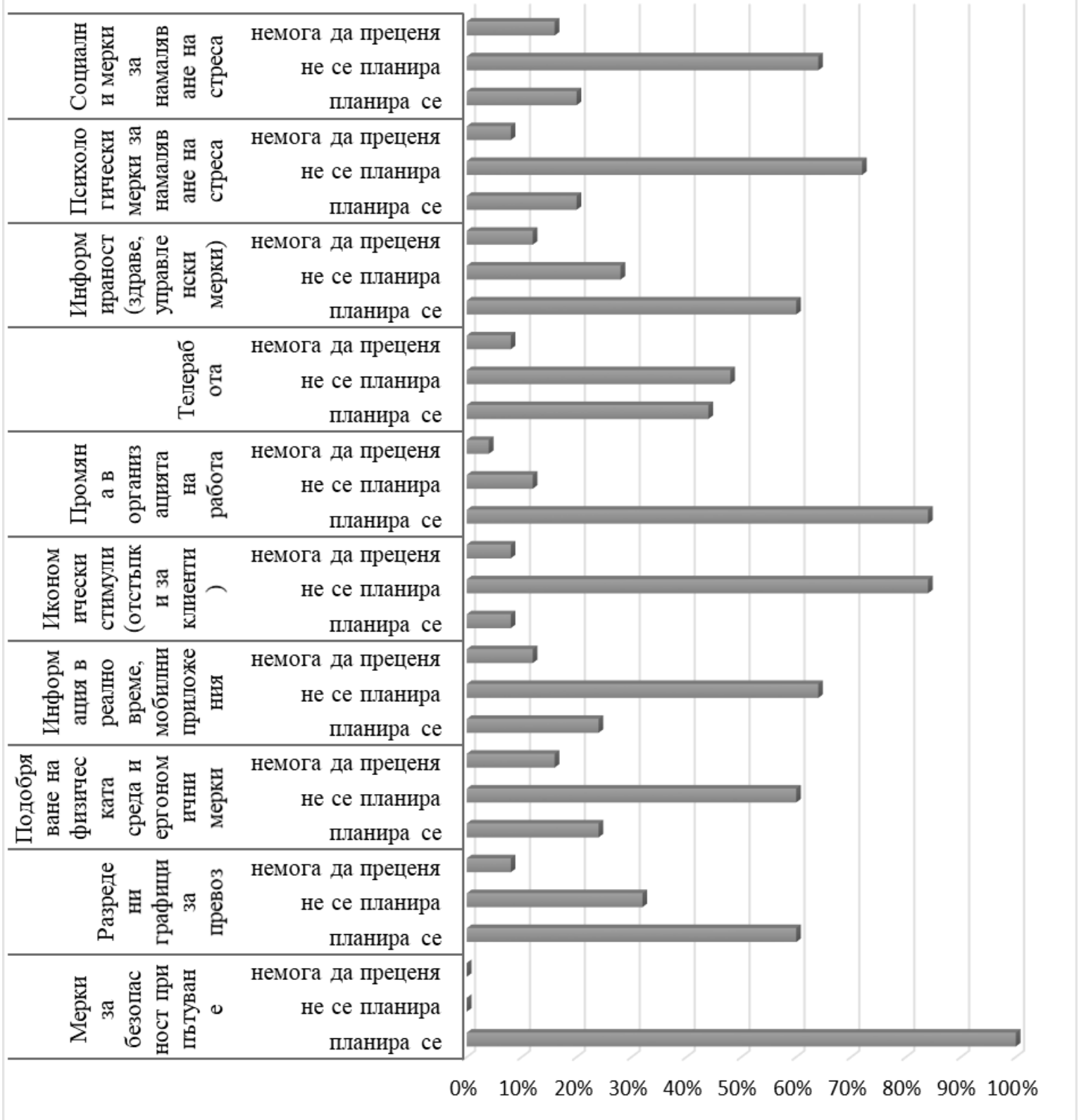

Фигура 1 Планирани мерки, свързани с психосоциалните рискови фактори в условия на COVID-19: емпирично проучване на автора 
Паралелно с планираната от всички предприятия мярка за осигуряване на безопасност при пътуване 84\% от респондентите възнамеряват да променят организацията на работа (работен график, работно време, смени, почивки), а $60 \%$ от предприятията ще разредят графиците си за пътуване, което ще свие дейността. Най- непопулярната мярка в кризисната ситуация е обмислянето и въвеждането на икономически стимули като отстъпки за клиентите и други възможности с временно действие в условия на криза и за периода след преодоляване на пандемията и излизане от кризисната ситуация.

На потенциала на съвременните информационни технологии и технически средства в условия на стопанска дейност в пандемия разчитат 24\% (6 предприятия), които ще разчитат и на електронните и мобилни приложения в работата с клиенти граждани.

Телеработата за част от специалистите с административни функции е в плана на 44\% от организациите (11 предприятия).

По отношение на намаляване на въздействието на свързаните с труда психосоичиални рискови фактори в условия на COVID-19 разпределението на отговорите на обхванатите в изследването организации е както следва:

(a) управленски мерки, насочени към повишаване на осведомеността: 60\% от респондентите (15 организации) декларират, че ще предоставят информация на служителите относно въпроси, свързани със здравето и свързаните с бизнеса мерки, които се превиждат за справяне със ситуацията;

(б) подобряване на физическата среда и ергономични мерки: подобни действия се предвиждат само в шест предприятия (24\%).

(в) мерки за психологическа подкрепа на специиалистите като мониторинг на стреса и програми за психологическа подкрепа: подобни действия се планират в $20 \%$ от респондентите (5 предприятия), 80\% не предвиждат ангажимент в оценка на риска по отношение на стреса за специалистите.

(г) мерки за соичилна подкрепа на специилистите като стимулиране от страна на ръководството на неформалните социални контакти чрез електронни средства, внимание от страна на ръководителите и признание за резулатите от специалистите: мальк е броя на предприятията, които планират специална подкрепа - 20\% от респондентите.

\section{4. Изводи и препоръки}

Пандемията COVID-19 оказва съществено въздействие върху организациите от сектор „транспорт“. Системите за обществен траспорт и организациите от тази сфера имат ключово значение за градската и междуселищната мобилност и са едни от големите работодатели. Операторите за обществен транспорт, както и предприятията за товарен транспорт и транспорт на туристи са задължени и стриктно спазват рестрикциите и нормативните предписания за намаляване на риска от разпространение и предпазване от COVID-19.

Направеното проучване и теоретичен анализ по проблематиката за психосоциалните рискови фактори на работното място позволяват да бъдат направени следните изводи:

(1) Кризата в резултат COVID-19 оказва изключително негативно въздействие върху финансовите резултати на организациите в сектор „транспорт“.

(2) Финансовите загуби са съчетани със съществено свиване на дейността за малките превозвачи, ориентирани основно към транспорт на туристи, част от които са съкратили специалисти.

Съществено предизвикателство за операторите за обществен транспорт и големите транспортни фирми за междуселищен, международен и товарен транспорт се явява обезпечаването на непрекъсваемост на транспортната дейност при спад на финансовите резултати, спазване на мерки за дезинфекция и отстояние, баланс „промени в работното време и график - необходим персонал“ и засилен психосоциален риск в резулат пандемията. Задълбочаването и усложняването на епидемичната обстановка би поставило на преден план 
проблема за справяне с висок процент отсъстващи от работа и осъществяване на дейността, както и със ситуация на завръщане на работа на специалисти след период на заболяване или карантина.

(3) Спецификата на бранша предполага осъществяване на трудова дейност на работното място и приложимост на дистанционни форми на работа по електронен път само за част от персонала с административни функции, когато естеството на задълженията го позволяват. Сравнително малка част от анкетираните организации са осъществили подобна мярка и/ или планират да я предприемат.

(4) По отношение на психосоциалните рискови фактори и ергономичността на средата респондентите се фокусират върху осигуряването на осведоменост, а сравнително непопулярни мерки се явяват подобряването на физическата среда, както и приложението на подходи за осигуряване на психологическа и социална подкрепа на специалистите. Това би оказало негативно въздействие върху степента, в която трудещите се са изложени на психосоциален риск.

В практико- приложен план могат да бъдат откроени следната необходимост от действие по отношение на управленските $u$ ергономичните мерки за намаляване на въздействието на психосоциалните рискови фактори в условия на COVID-19:

(1) Осигуряване на форми за публична финансова подкрепа чрез програми за подкрепа на бизнеса в сектор „транспорт“, включително и мерки, свързани с трудовите процеси, оценка на риска и редуциране на въздействието на психосоциалните рискови фактори и активност на организациите за кандидатстване за финансиране и подкрепа.

(2) Насърчаване на използването на иновативния потенциал на съвременните информационни и комуникационни технологии в градската и междуселищна мобилност, както и обмисляне на възможността за икономически стимули с цел избягване на струпването на пьтници.

(3) Оценка и анализ на риска с особен акцент върху психосоциалния риск на работното място и осъществяване на превантивни мерки:

- Избягване на свръхнатовареността на специалистите и удълженото работно време в резултат евентуална необходимост за работа в намален състав. В процеса на анализ на породеното от трудова дейност умствено и физическо натоварване на специалистите трябва да се отчита естеството на задълженията: административни задължения или шофиране. Самият характер на дейността „шофиране“ е свързан с повишено нервносензорно напрежение и е предпоставка за стрес.

- Обмисляне на възможността за наемане на лица на временна заетост при отсъствия на титулярите за длъжността.

- Анализ на процесите на труд и използване на инструментариума на управление на времето при разработване на график;

- Подкрепа от ръководството и признание за дейността и постигнатото.

- Специални мерки за специалисти с хронични заболявания.

- Търсене на възможности за телеработа при предоставяне на специалистите на необходимите технически средства, гъвкавост при работното време с оглед запазване баланса „труд -свободно време/ семеен живот“ и указания за ергономичност на средата, работна поза и двигателна активност; комуникация;

- Социална подкрепа за специалистите: електронни форми за неформална

- Програми за психологическа подкрепа;

- Информираност и комуникация с персонала по въпроси, свързани със здравето и при предприемане на промени, реорганизация и свиване на бизнеса. 
(4) Разработване на план за действие в кризисна ситуация и при необходимост предприемане на спешни корективни мерки с цел осигуряване на благоприятна психосоциална среда.

\section{Заключение}

В съвременната организация проблематиката за психосоциалните рискови фактори и възможностите за тяхното редуциране чрез управленски и ергономични мерки придобива особена актуалност в контекста на технологичното развитие, дигиталната трансформация и променения работен свят. Пандемията, породена от COVID-19, постави предизвикателства пред организациите от всеки бранш, включително и от сферата на транспорта. В тази кризисна ситуация предмет на оценка, анализ и управленско въздействие следва да бъдат не само възможностите за оцеляване на бизнеса, а и новите психосоциални рискове на работното място. В условия на COVID-19 чувствителността на организациите към социалните проблеми, приложението на подходи за тяхното преодоляване и тьрсенето на възможности за формиране на благоприятна психосоциална работна среда е въпрос от първостепенно значение, както за теоретичните търсения в областта на мениджмънта и безопасните и здравословни условия на труд, така и за практиката на управлението.

\section{References}

1. European Social Partners (2004) Framework agreement on work-related stress. ETUC, UNICE (BUSINESSEUROPE), UEAPME and CEEP, Brussels. Available from: https://www.businesseurope.eu/publications/european-social-partners-framework-agreementwork-related-stress [Accessed 27/10/2020]

2. Eurofound (2012) Health and well-being at work: A report based on the fifth European Working Conditions Survey, Dublin. Available from: https://www.eurofound.europa.eu/sites/default/files/ef_publication/field_ef_document/ef1302en .pdf [Accessed 28/10/2020]

3. European Agency for Safety and Health at Work. Healthy Workplaces (2018) Managing stress and psychosocial risks E- guide. Available from: https://osha.europa.eu/en/tools-andresources/e-guides/e-guide-managing-stress-and-psychosocial-risks [Accessed 28/10/2020]

4. European Agency for Safety and Health at Work (2018) Healthy workers, thriving companies a practical guide to wellbeing at work. Tackling psychosocial risks and musculoskeletal disorders in small businesses. Luxembourg. Available from: https://doi.org/10.2802/237140 [Accessed 28/10/2020]

5. International Labor Office (1986) Psychosocial factors at work: recognition and control. Report of the Joint International Labor Office and World Health Organization on Occupational Health, Ninth Session, Geneva, 18-24 September 1984. Occupational Safety and Health Series No. 56. International Labour Office, Geneva.

6. Leka, St., Jain, A., Widerszal- Bazyl, M., Zolnierczyk- Zreda, D., Zwetsloot, G. (2011) Developing a standard for psychosocial risk management: PAS 1010. Safety Science. 49, pp. $1047-157$

7. International Organisation for Standardisation (1996) EN ISO 10075-2: Ergonomic principles related to work-load - Design principles. International Organisation for Standardisation, Geneva.

8. International Labour Organisation (2012) Stress prevention at work checkpoints. Practical improvements for stress prevention in the workplace. Geneva

9. Karasek, R. (1979). Job Demands, Job Decision Latitude, and Mental Strain: Implications for Job Redesign. Administrative Science Quarterly, 24 (2), 285-308

10. Karasek, R., Theorell, T. (1990) Healthy Work: Stress, Productivity, and the Reconstruction of Working Life. New York: Basic Books 
11. Siegrist, J. (2002) Effort-reward imbalance at work and health. In P. L. Perrewé \& D. C. Ganster (Eds.). Research in occupational stress and well-being. Vol. 2. Historical and current perspectives on stress and health, pp. 261-291

12. Paskvan, M. Kubicek, B (2017) The Intensification of Work. In Korunka Chr., Kubicek, B (Ed.) Job demand in a Changing World of Work. Impact on Workers Health and Performance and Implications for Research and Practice. Springer Switzerland

13. Albertsen K, Rugulies R, Garde AH, Burr H (2010) The effect of the work environment and performance-based self-esteem on cognitive stress symptoms among Danish knowledge workers. Scand J Public Health. 38(3), pp. 81-89

14. Llorens C, Alós R, Cano E, Font A, Jódar P, López V. (2010) Psychosocial risk exposures and labour management practices: an exploratory approach. Scand J Public Health. 38(3), pp. 12536

15. Kiss, Ph., De Meester, Kruse, A., Chavee, B., Braeckman, L. (2013) Comparison between the first and second versions of the Psychosocial Quesionnaire: psychosocial risk factors for a need for recovery after work. International Archives of Occupational and Environmental Health. 86, pp. 17-24

16. Fernandes, C., Pereira, A. (2016) Exposure to psychosocial risk factors in the context of work: a systematic review. Revista Saúde Pública. 50-24

17. International Labor Organization (2020) ILO Monitor: COVID-19 and the world of work. Sixth edition. Available from: https://www.ilo.org/global/topics/coronavirus/impacts-andresponses/WCMS_755910/lang--en/index.htm [Accessed 28/10/2020]

18. International Labor Organization (2020) Managing work-related psychosocial risks during the COVID-19 pandemic. Geneva Available from: https://www.ilo.org/global/topics/safety-andhealth-at-work/resources-library/publications/WCMS_748638/lang--en/index.htm [Accessed 28/10/2020] 